\title{
Pengungkapan Aspek Matematis pada Aktivitas Etnomatematika Produksi Ecoprint di Butik El Hijaaz
}

\author{
Ratih Puspasari $^{*}$, Anis Rinawati ${ }^{2}$, Anung Pujisaputra ${ }^{3}$ \\ Pendidikan Matematika, Universitas Bhinneka PGRI \\ Jalan Mayor Sujadi Timur No. 07, Tulungagung, Jawa Timur, Indonesia \\ 1*ratihpuspasari8@gmail.com; ${ }^{2}$ anissyauqi@yahoo.com; ${ }^{3}$ anungsaputra27@gmail.com
}

Artikel diterima: 08-09-2020, direvisi: 26-09-2021, diterbitkan: 30-09-2021

\begin{abstract}
Abstrak
Butik El Hijaaz merupakan pengrajin kain ecoprint di Tulungagung yang mengembangkan teknik ecoprint menggunakan bahan alam sebagai pewarna kain dan pencetak motif yang ramah lingkungan. Penelitian dilakukan untuk mengungkap aspek matematika yang terkandung dari proses pembuatan kain ecoprint, seperti membilang, mengukur, mendesain. Tujuan dari penelitian ini adalah mengungkap aspek-aspek matematis dan aktivitas-aktivitas fundamental matematis yang terdapat dalam aktivitas ecoprint di butik El Hijaaz Tulungagung. Penelitian ini menggunakan pendekatan kualitatif dengan metode etnografi yakni observasi, wawancara, dokumentasi. Subjek penelitian yaitu karyawan butik dan pemilik Butik El Hijaaz. Lokasi penelitian yaitu di butik El Hijaaz Kabupaten Tulungagung. Hasil penelitian menunjukan bahwa: 1) aktivitas fundamental yang ditemukan pada proses pembuatan kerajinan kain ecoprint di Galery El Hijaaz antara lain counting, measuring, design, locating, playing dan explaining. 2) Konsep matematis yang dapat diungkap adalah perbandingan, konversi waktu, konversi suhu, konsep membilang, himpunan, konsep pecahan, konsep pengukuran, refleksi, kesebangunan, kongruensi, program linier, aritmatika sosial.

Kata Kunci: aspek fundamental matematis, ecoprint, ethnomatematika.

\section{Disclosure of Mathematics Aspects on Ethnomathematics Activities of Ecoprint Production in El Hijaaz Boutique}

Abstract

Butik El Hijaaz is an ecoprint fabric craftsman in Tulungagung who develops ecoprint techniques using natural materials as fabric dyes and prints environmentally friendly motifs. The research was conducted to reveal the mathematical aspects contained in the process of making ecoprint fabrics, such as counting, measuring, designing. The purpose of this research is to reveal the mathematical aspects and mathematical fundamental activities contained in the ecoprint activity at El Hijaaz boutique Tulungagung. This study uses a qualitative approach with ethnographic methods namely observation, interviews, documentation. The research subjects are boutique employees and El Hijaaz Boutique owners. The research location is the EI Hijaaz boutique, Tulungagung Regency. The results of the study show that: 1) the fundamental activities found in the process of making ecoprint fabrics at the El Hijaaz Gallery include counting, measuring, design, locating, playing and explaining. 2) Mathematical concepts that can be revealed are comparison, time conversion, temperature conversion, counting concept, set, fraction concept, measurement concept, reflection, similarity, congruence, linear program, social arithmetic.

Keywords: fundamental aspects of mathematics, ecoprint, ethnomathematics.
\end{abstract}




\section{Pendahuluan}

Di era modern saat ini kesenian kerajinan kain mengalami perkembangan yang sangat pesat. Hal ini dipengaruhi oleh seiring meningkatnya kesadaran masyarakat dalam menjaga kelestarian alam, sehingga teknik produksi yang dipilih menggunakan bahan yang ramah lingkungan. Trend gaya hidup ramah lingkungan ini semakin digemari masyarakat dan potensial untuk pengembangan eco fashion (Rumah Yapeka, 2019). Eco Fashion (Fashion Ramah Lingkungan) merupakan konsep pakaian yang mengacu kepada semua produk fashion yang diciptakan untuk menciptakan lingkungan yang lebih sehat, bersih dan seimbang (Hana, 2021).

Seiring berkembangnya zaman, teknik pewarnaan kain dengan bahan alam berkembang dengan berbagai temuan baru, salah satunya adalah teknik eco dyeing dan eco printing (Wirawan \& Alvin, 2019). Teknik ini telah berkembang sejak lama, dan dipopulerkan sejak tahun 2006 salah satunya oleh Indiana Flint. Berasal dari teknik eco dyeing lalu Flint mengembangkannya menjadi Teknik ecoprint (Saraswati dkk., 2019a).

Proses ecoprint merupakan suatu proses yang unik yaitu melalui pengukusan (steam) untuk memunculkan bentuk daun dan warna dari bahan alam (tumbuhan). Corak yang dihasilkan dari teknik ecoprint tak jarang menghasilkan warna dan corak yang tak terduga. Kadang daunnya hanya tercetak dengan warna putih saja tanpa tercetak tulang-tulang daunnya. Kadang bisa semua tercetak dari mulai daunnya sampai kelopak daunnya tercetak semua di kain. Dengan demikian sangat sulit apabila ingin membuat kain dengan jumlah yang banyak dengan corak dan warna yang sama. Hal inilah yang membedakan kain hasil buatan masal secara pabrikan dengan kain bukan buatan massal yang dibuat oleh pengrajin (Saraswati dkk., 2019b).

Hasil observasi peneliti dengan Ibu Elis owner dari Galeri El Hijaaz yang berlokasi di daerah Rt 03 RW 02 dusun, Tambak Kembang, Tambakrejo, Kecamatan Sumber Gempol, Kabupaten Tulungagung, Jawa Timur, adalah untuk membuat karya ecoprint yang indah, seorang ecoprinter harus memiliki kemampuan mengingat jenis karakter daun, bunga, dan batang pada tumbuhan yang memiliki zat warna alam (ZWA), menghitung takaran (kompisis) bahan -bahan alam yang digunakan untuk membuat pewarna alam sesuai dengan keinginan, mengukur suhu dan waktu saat proses steaming, mengukur panjang dan lebar media (kain \& tongkat), dan kemampuan mendesain pola agar motif daun, bunga, dan batang yang muncul pada permukaan kain atau kulit bisa tercetak dengan jelas.

Dari penjelasan ibu Eliz tersebut, peneliti meyakini ada keterkaitan antara pembuatan kerajinan kain ecoprint di Galery El Hijaaz dengan aktivitas fundamental matematis menurut Bishop. Hal ini dibuktikan dengan keterampilan 
dalam menentukan perbandingan komposisi bahan - bahan alam dengan air untuk membuat larutan scouring dan larutan mordanting sebelum membuat kerajian kain ecoprint. menentukan harga jual produk, menghitung rugi laba. menentukan upah pegawai, dsb.

Dari aktivitas tersebut telah menunjukkan adanya keterkaitan hubungan antara budaya yang telah berkembang di suatu daerah dengan matematika yang dikenal dengan nama etnomatematika (Lisnani, dkk., 2020; Astriandini \& Kristanto, 2021; Nursyeli \& Puspitasari, 2021). Istilah Ethnomatematika ditemukan oleh D’Ambrisio, seorang matematikawan asal Brazil pada tahun 1977. D’Ambrosio, (1985) mengemukakan bahwa: "ethnomathematics the mathematics which is practised among identifiable cultural groups, such as national-tribal societies, labor groups, children of a certain age bracket, professional classes, and so on." Dalam Rosa \& Orey (2011) mengatakan bahwa the term 'ethnomathematics' has been used by D'Ambrosio (1985) to mean "the mathematical practices of identifiable cultural grouphs and may be regardes as the study of mathematical ideas found in any culture". Pendapat D' Ambrosio dapat diartikan sebagai penggunaan matematika dari sekelompok budaya yang dapat diidentifikasi dan dapat dianggap sebagai suatu studi dari matematika yang ditemukan dalam berbagai budaya.
Albanese \& Perales

(2015:2) mengungkapkan bahwa: "Ethnomathematics is a research program that focuses on the relationships between mathematics and culture". Yang berarti bahwa etnomatematika merupakan program penelitian dimana yang menjadi fokusnya yaitu pada hubungan antara matematika dan budaya.

Menurut Bishop (1991) terdapat 6 fundamental mathematical activities (6 aktivitas dasar matematika) yang terdiri dari counting (membilang), locating (menentukan lokasi), measuring (mengukur), designing (merancang), playing (bermain) dan explaining (menjelaskan). Kemudian dari aktivitasaktivitas fundamental yang didapat tersebut diperoleh aspek-aspek matematis yang terdapat didalamnya.

Beberapa penelitian yang sudah dilakukan dengan pengkajian aktivitas fundamental matematis menurut Bishop diantaranya Krisnawati, (2017) dengan judul "Kajian Etnomatematika terhadap Tradisi Pernikahan Yogyakarta oleh Masyarakat di Kecamatan Minggir, Sleman, DIY, dalam Rangka Penentuan Aspek-Aspek Matematis yang dapat Digunakan dalam Pembelajaran Matematika di SMP. Gunawan, (2019) dengan judul "Kajian Etnomatematika serta analisis aktivitas fundamental matematis menurut Bishop pada industri Kain Cual Bangka Belitung". Fatimah \& Sirate (2011) dengan judul "Studi Kualitatif 
tentang Aktivitas Etnomatematika dalam Kehidupan Masyarakat Tolaki.

Dari uraian pendapat di atas semakin jelas bahwa ada keterkaitan antara budaya dengan matematika. Sehingga urgensi peneltian ini sangat perlu dilakukan untuk mengungkap aktivitas fundamental matematis yang terdapat pada produksi kerajinan ecoprint dan mengungkap aspekaspek matematis apa saja yang relevan pada kegiatan pembuatan kerajinan kain ecoprint.

\section{Metode}

Penelitian ini menggunakan metode deskriptif kualitatif. Sebagai langkah awal penelitian, data tentang Ecoprint dikumpulkan dari berbagai sumber literatur. Dalam menetapkan informan, penelitian ini menggunakan purposive sampling dengan memperhatikan syaratsyarat yang harus dipenuhi untuk menjadi informan sehingga diperoleh seorang informan yang mampu bekerja sama dengan baik. Informan yang dipilih dalam penelitian ini adalah pemilik dari Galery EL Hijaaz yaitu ibu Elis Zulfa Mastuti.

Penelitian ini menggunakan trianggulasi sumber dengan mewawancarai Ibu Elis Mastuti selaku pemilik Butik El Hijaaz. Data tersebut terkait dengan aktivitas dan konsep matematika. Teknik pengumpulan data penelitian ini dilakukan dengan melakukan observasi, wawancara dan dokumentasi. Analisis data dilakukan secara induktif, yaitu suatu analisis berdasarkan data yang diperoleh.
Selain itu, penelitian ini menggunakan pendekatan etnografi karena mempelajari kehidupan sosial dalam suatu masyarakat. Creswell, (2012). Penelitian kualitatif dengan pendekatan etnografi ini, yang menjadi instrumen penelitian adalah Human instrument, yaitu peneliti berperan sebagai instrumen utama yang tidak dapat digantikan atau diwakilkan orang lain.

\section{Hasil dan Pembahasan}

Kajian etnomatematika dalam penelitian ini berupa analisis aktivitas fundamental matematis yang termuat dalam proses produksi kerajinan kain ecoprint. Aktivitas Counting (menghitung/ membilang) merupakan salah satu aktivitas yang sering dilakukan masyarakat, berkaitan dengan banyaknya sesuatu, jawaban dari pertanyaan berapa banyak ? (Aini, 2021). Locating (penentuan lokasi) adalah penentuan suatu posisi titik/objek tertentu (Aini, 2021). Aktivitas measuring (mengukur) lebih dikaitkan pada kata tanya "berapa" seperti panjang, berat, luas, tinggi, dan sebagainya (Aini, 2021). Aktivitas Designing (pendesainan) yang dilakukan masyarakat berkaitan dengan kegiatan membuat rancang bangun telah diterapkan (Hartoyo, 2011). Aktivitas Playing (bermain) merupakan kegiatan yang sifatnya menyenangkan, mempunyai pola tertentu dan mendorong seseorang untuk mengatur strategi (Aini, 2021). Aktivitas Explaining (menjelaskan) merupakan aktivitas yang biasanya dikaitkan pada kata tanya "mengapa" 
dalam membaca fenomena alam (Aini, 2021).

Berdasar hasil analisis diperoleh proses produksi kerajinan kain ecoprint memuat enam aktivitas fundamental matematis dari Bishop yang akan diuraikan di bawah ini.

\section{A. Explaining}

Belum ada data yang pasti kapan kerajinan kain ecoprint masuk ke Indonesia. Ada yang berpendapat bahwa awal munculnya ecoprint bermula saat desainer Indonesia Novita Yunus berkesempatan mewakili Indonesia mengusung busana ecoprint di ajang event Fashion Internasional, Amazon India Fashion Week Autumn/ Winter di India tahun 2017. Novita, mengungkap tema yang akan diangkat terinspirasi dari keindahan Langit dan Bumi. Novita menganggap langit sebagai simbol dari kemenangan yang menawarkan desain warna-warna yang menakjubkan (Wulan, 2017).

Motif yang dihasilkan dari proses tehnik ecoprint ini menunjukkan bentuk motif apa adanya dari flora (karena bahan motif yang digunakan adalah bahan asli dari alam, misalnya daun, bunga dan batang). Dengan penyusunan motif yang bebas sehingga motif kain ecoprint ini tidak mengandung makna simbolik atau makna secara khusus, sehingga termasuk ke dalam motif modern. Beberapa desainer menyebutnya motif ecoprint ini tergolong dalam desain tekstil flora.

\section{B. Acounting}

Aktivitas acounting terdapat pada kegiatan menghitung kebutuhan alat dan bahan baku untuk membuat 1 kain ecoprint, yaitu kain katun, bahan-bahan alam untuk membuat pewarna alam, tumbuh-tumbuhan (pencetak motif ecoprint) dan plastik. Jika motif yang diinginkan penuh warna warni maka kebutuhan bahan alam dan unsur tumbuhtumbuhan untuk motif kain juga banyak. Konsep matematis pada kegiatan menghitung kebutuhan alat dan bahan adalah membilang

Aktivitas acounting juga muncul saat pengrajin akan memotong kain guna memenuhi pesanan. Kain yang dipotong berupa kain roll katun jenis rayon. 1 roll kain=50 yard. Bila 1 yard $=0,9144 \mathrm{~m}$, maka 50 yard $=45,72 \mathrm{~m}=45 \mathrm{~m}$ (pembulatan). Sebelum memotong, pengrajin terlebih dahulu membagi 1 roll kain dengan ukuran masing-masing 1,5 m. Sehingga diperoleh $45: 1,5=30$. Jadi 1 roll kain diperoleh 30 potong kain siap pakai.

Plastik yang digunakan untuk proses steam diukur sesuai dengan panjang kain. Untuk 1 kali produksi kain dan plastik yang disiapkan masing-masing 1 pasang. Konsep matematis yang muncul saat proses memotong kain dan plastik adalah pembagian, perkalian, membilang.

Aktivitas acounting juga ada saat menghitung perbandingan larutan scouring, mordant, pewarna alam, treatment kain dan daun serta larutan 
fiksasi. Proses scouring menggunakan TRO dicampur dengan air biasa. Takaran perbandingan TRO : air $=10$ gram $: 2$ liter.
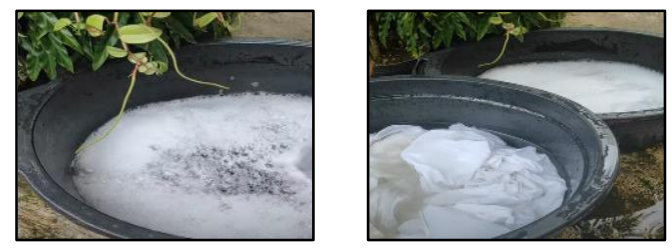

Gambar 1. Proses Scouring.

Takaran larutan ini cukup untuk 1 potong kain dengan panjang $\pm 1,5$ meter kain (dapat disesuaikan). Kain direndam selama 20-30 menit, selanjutnya kain dibilas lalu dijemur hingga kering. Bila kain yang hendak di scouring sebanyak 10 potong, maka bahan yang dibutuhkan sebanyak 100 gram TRO dan 20 liter air. Konsep matematis yang ada pada aktivitas ini adalah konsep perkalian, waktu, perbandingan, penjumlahan.

Aktivitas Acounting muncul saat proses pembuatan larutan mordant. Perbandingan bahan untuk larutan mordant tawas adalah = tawas : soda abu : air $=14$ gram : 6 gram : 1 liter. Takaran ini cukup untuk 1 meter kain. Caranya adalah air dimasak sampai sekitar $80^{\circ} \mathrm{C}$, kemudain tawas dan soda abu dicampur dalam rebusan air sambil diaduk-aduk sampai larut, setelah larut maka masukkan kain katun dan masak selama kurang lebih 1 jam. Setelah 1 jam panci diangkat kemudian dibiarkan selama 6 jam atau hingga menunggu benar benar dingin. Selanjutnya kain dibilas dan keringkan.
Kain siap digunakan setelah 2 minggu dari proses mordanting.

Aktivitas acounting muncul saat menghitung perbandingan bahan alam untuk membuat pewarna alami. Dan biaya yang dibutuhkan untuk belanja bahan alam.
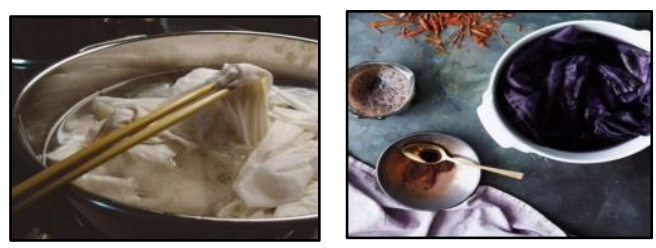

Gambar 2. Proses Mordanting.

Takaran untuk membuat pewarna alam adalah dengan mencampur $1 \mathrm{~kg}$ bahan pewarna alam dengan air bersih 6 liter, 3 sendok makan garam dapur, dan 3 sendok makan symplocos. Bahan yang sudah dicampur tersebut direbus hingga air tersisa 50\%, atau apabila ingin lebih kental maka bisa disisakan hingga \pm 2 Liter. 2 liter zat warna alam (ZWA) ini cukup untuk memberi warna 1 potong kain dengan ukuran 2 meter.
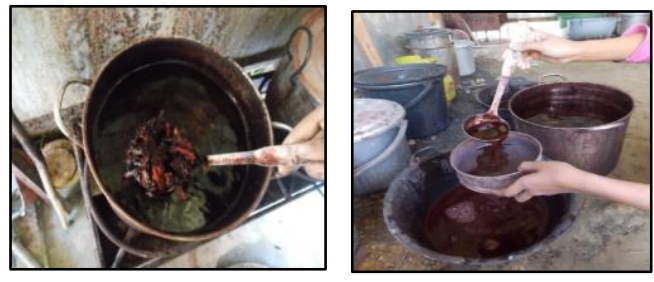

Gambar 3. Proses membuat pewarna alami.

Untuk membuat 2 liter pewarna alam yang pekat dibutuhkan 3 sendok symplocos. 3 sendok symplocos setara dengan 45 gram. Konsep matematis yang muncul pada aktivitas membuat larutan pewarna alami adalah membilang, 
perbandingan, persentase, penjumlahan, perkalian, pembagian.

Aktivitas acounting juga muncul pada saat membuat larutan treatment daun dan treatment kain. Untuk membuat larutan treatment daun bahan yang dibutuhkan yaitu dengan mencampur 6 sendok makan cuka meja dengan 1.5 liter air bersih. Selain cuka, bisa menggunakan serbuk tunjung (Alum), dengan cara melarutkan 4 sendok makan serbuk tunjung (alum) dengan 1 liter air biasa. Daun-daun bisa direndam dengan waktu 15 menit sampai sehari semalam tergantung tebal tipis kondisi daun. Konsep matematis yang muncul pada aktivitas membuat larutan treatment daun adalah perbandingan, dan konversi berat.

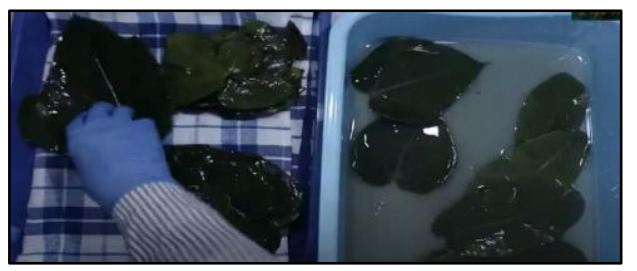

Gambar 4. Treatment Daun.

Untuk membuat larutan treatment kain bahan yang digunakan adalah tunjung, tawas dan kapur. Untuk 1 potong kain dengan ukuran 2 meter, maka bahan yang dibutuhkan adalah 3 gram tunjung dan 1 liter air biasa untuk 2 meter kain; tawas 6 gram untuk 1 liter air biasa untuk 2 meter kain; kapur 500 gram ditambah 15 liter air (3 liter air panas +12 liter air dingin) diamkan seminggu sehingga air endapan lebih bening dan siap dipakai. Air endapan yang dipakai \pm 2 liter.
Cara melakukan treatment kain dengan mencelup kain ke dalam larutan tunjung atau tawas atau kapur selama 10 detik selanjutnya diperas hingga kandungan air seakan-akan tidak ada lagi yang menetes. Konsep matematis yang muncul pada proses treatment kain adalah perbandingan, penjumlahan, pengurangan, dan waktu.

Aktivitas acounting juga muncul pada saat membuat larutan fiksasi. Perbandingan bahan yang digunakan untuk membuat larutan fiksator antara lain: a) tunjung 3 gram / liter air; b) tawas 3 sdm / 3 L air; c) cuka 80 ml / 2 liter; d) 2 Liter air endapan kapur.

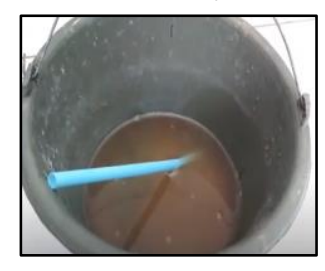

Gambar 5. Fiksasi Tunjung.

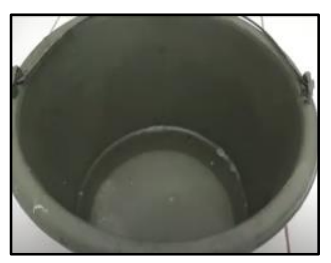

Gambar 6. Fiksasi Tawas.
Cara menggunakannya adalah dengan merendam kain ke dalam larutan fiksasi yang diinginkan selama 5 menit. Konsep matematis yang muncul pada proses fiksasi adalah perbandingan, penjumlahan dan waktu.

Aktivitas acounting juga muncul saat memperkirakan waktu penyelesaian satu potong kain ecoprint. Untuk sekali produksi dibutuhkan 2 kain. Yaitu 1 kain utama dan 1 kain blanket. Sehingga dalam 1 produksi diperoleh 2 kain. Sebelum kain digunakan, sebaiknya kain sudah dimordant dulu 2 minggu sebelumnya. 
Setelah melalui proses penataan daun dan steam selanjutnya kain baru bisa dibuka. Setelah kain di buka maka kain tersebut diangin-anginkan hingga kering (proses oksidasi alami) selama 1 minggu. Setelah 1 minggu kain tersebut baru dapat difiksasi (penguncian warna). Jadi total waktu yang dibutuhkan untuk menyelesaikan 1 potong kain ecoprint adalah 3 minggu. Konsep matematis yang muncul saat memperkirakan waktu penyelesaian satu potong kain ecoprint adalah membilang dan menjumlah.

Aktivitas acounting juga muncul saat menghitung harga jual kain ecoprint berdasarkan bahan utama kain, pewarna alam dan proses produksinya. Penentuan harga kain dihitung berdasarkan perhitungan Harga Pokok Produksi. Untuk kisaran harga 1 potong bila kain yang diminta menggunakan sutera maka harga jual 1 potong kain sutera nya minimal Rp. 2.500.000,-. Karena harga kain sutra juga sudah mahal. Bila menggunakan kain katun rayon, harga 1 potong kain katun rayon minimal Rp. 500.000,-.Konsep matematis yang muncul adalah konsep membilang, penjumlahan, dan perkalian.

Aktivitas acounting juga muncul saat menghitung upah pekerja. Upah pekerja diberikan sesuai dengan spesialisasinya. Dan dihitung seberapa banyak potongan kain yang dikerjakan dalam sehari. Sehingga setiap pekerja akan menerima upah yang berbeda. Upah dibayarkan mingguan. Bila 1 hari mendapatkan upah Rp. 60.000 maka 1 minggu (6 hari) mendapatkan Rp.60.000,- x $6=$ Rp. $360.000,-$. Konsep matematis yang muncul adalah membilang, penjumlahan, dan perkalian.

\section{Measuring}

Aktivitas measuring ditemukan saat pengrajin ecoprint akan memotong kain dan plastik serta membuat takaran larutan. Alat ukur yang digunakan adalah menggunakan meteran kain, termometer, timbangan dan juga sendok makan. Pengrajin membagi ukuran kain dan plastik dalam satuan standar yard dan meter. Sedangkan saat pengrajin membuat larutan-larutan scouring, mordant, treatment, pewarna alam, dan fiksasi, takaran ukuran standart yang digunakan mengukur bahan alam dan air adalah gram, liter, cc, dan derajat celsius. Dan ukuran konvensional yang digunakan adalah menggunakan takaran sendok makan. Sedangkan waktu yang dibutuhkan untuk proses produksi menggunakan ukuran detik, menit, jam dan hari. Konsep matematis yang muncul pada aktivitas mengukur adalah panjang, berat, volum, suhu, dan waktu.

\section{Designing}

Aktivitas Designing terlihat ketika merencanakan menentukan warna alam apa yang akan digunakan. Ada warnawarna alam yang dihasilkan dari bahan alam. Seperti green tea (hijau), Tegeran (kuning), tingi (merah gelap kecoklatan), jambal (coklat kemerahan), (kulit manggis (merah keunguan), secang (merah), dll. 
Aktivitas designing juga terlihat saat menentukan bahan alam apa yang digunakan untuk proses mordanting dan fiksasi. Proses mordant memiliki teknik yang berbeda beda baik komposisi bahan maupun tahapan-tahapannya. Karena antara teknik yang satu dengan teknik yang lain akan menghasilkan pewarnaan yang berbeda-beda.

Proses designing juga terlihat saat menentukan bahan alam apa yang digunakan untuk proses fiksasi. Masingmasing fiksator menghasilkan efek berbeda disetiap kain yang difiksasi. Warna yang dihasilkan oleh daun atau bunga tersebut dapat menurun $\pm 25 \%$ setelah proses penguncian/fixsasi. Konsep matematis pada aktivitas ini adalah peluang kejadian.

Proses designing juga terlihat pada kegiatan menata daun, bunga dan batang pada kain utama untuk membuat motif. Daun yang memiliki kandungan tanin yang cukup tinggi mudah mengeluarkan warna dan jejak pada kain menjadi 1 kelompok tidak perlu dicelupkan dalam larutan treatment. Beberapa daun dan bunga yang tidak memiliki kandungan tanin rendah memerlukan treatment terlebih dahulu. Konsep matematis pada aktivitas ini adalah himpunan (menyatakan himpunan).

Setelah direndam dalam larutan treatment daun selanjutnya daun, bunga dan batang ditata dengan komposisi penuh. Peletakan daun sangat bebas, dalam arti dapat dikreasikan menjadi berbagai bentuk lain, misalnya dengan pola miring (diagonal), orizont, orizontal, memusat, bergelombang atau acak. Hal tersebut akan menambah variasi desain susunan motif, ditambah lagi ukuran daun tentunya berbeda-beda, sehingga apabila dikombinasikan, akan membentuk hasil yang bagus. Dengan memberi sentuhan "rasa" yang sempurna, maka akan membentuk satu pola yang indah.

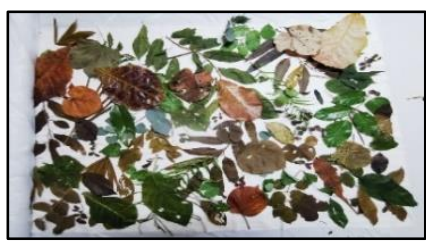

Gambar 7. Menata daun.

\section{E. Playing}

Aktivitas playing terdapat pada penentuan teknik ecoprint yang digunakan. Tehnik ecoprint ada 3 yaitu tehnik pounding (dipukul), tehnik steam (dikukus), dan infuse daun. Untuk mendapatkan hasil yang bagus masing masing teknik ini memiliki cara atau aturan tersendiri. Untuk pesanan dalam skala besar biasanya menggunakan teknik steam dengan cara sebagai berikut.

Sebelum dikukus terlebih dahulu menyiapkan sepasang plastik untuk alas dan juga tutup sebesar kain agar kain tidak kotor. Plastik dibentangkan ditempat yang rata dan cukup, disusul kain utama.

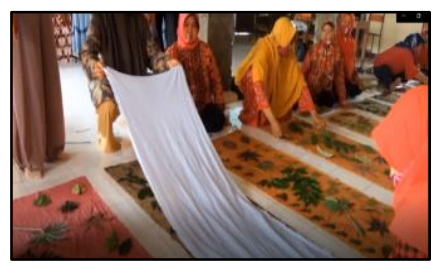

Gambar 8. Peletakan kain dan daun. 


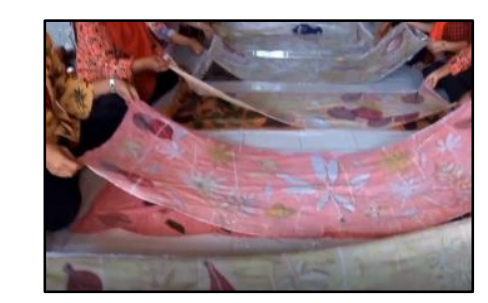

Gambar 9. Membuka kain ecoprint.

Daun ditata sesuai keinginan bisa membentuk motif bisa juga abstrak. Selanjutnya ditutup kain blanket dan plastik sebagai penutupnya. Selanjutnya kain dilipat simetris dan digulung membentuk lontong agar memudahkan masuk ke panci kukusan. Masukkan dalam steamer / kukusan selama 2 jam. Setelah 2 jam, keluarkan lontong kain dan dibuka dengan hati-hati. bersihkan daun yang menempel dan angin-anginkan kain hingga kering (proses oksidasi alami). Konsep matematis yang muncul adalah refleksi, pesegi panjang, kongruensi, kesebangunan, waktu.

\section{F. Locating}

Aktivitas locating terdapat pada penentuan penyuplai bahan baku kebutuhan ecoprint dan penempatan karyawan dalam proses produksi. Informasi yang diperoleh dari pekerja ibu Elis adalah Galery El Hijaaz sudah biasa membeli bahan baku di tempat yang khusus menyediakan kebutuhan utama ecoprint. Biasanya bahan baku didatangkan dari Solo dan Yogyakarta. Pemilihan lokasi dikarenakan di daerah tersebut banyak sekali yang menyediakan penjualan kain beraneka jenis. Ada yang kain katun, kain tenun maupun kain sutra yang dijual sesuai dengan kebutuhan kita. Pemilihan tempat ini juga didasari dengan harga yang relatif lebih murah dan kwalitasnya tinggi.

Penempatan karyawan dalam proses produksi juga dilakukan sesuai dengan spesialisasinya masing-masing. Untuk pekerja laki-laki bertugas meramban atau mencari tumbuh-tumbuhan dan membuat pewarna alami, proses fiksasi, penjemuran dan juga packagung. Untuk pekerja wanita melakukan proses scouring, mordant, menata daun, menggulung kain serta mengukus.

\section{Penutup}

Proses pembuatan kain ecoprint terdapat aktivitas fundamental matematis dan konsep matematika. Adapun aktivitas fundamental matematis menurut Bishop yang dapat ditemukan dalam kegiatan produksi kain ecoprint di galery El Hijaaz meliputi aktivitas counting, locating, measuring, designing, playing dan explaining. Sedangkan konsep matematis yang ditemukan dalam proses produksi ecoprint adalah konsep perbandingan, penjumlahan, pengurangan, pembagian, perkalian, konversi panjang, konversi waktu, konversi suhu, konversi berat, himpunan, konsep, kesebangunan, kongruensi, program linier, aritmatika sosial. 


\section{Daftar Pustaka}

Aini, F. (2021). Kajian Etnomatematika terhadap Tradisi Weh-wehan di Kecamatan Kaliwungu Kendal. Jurnal Pendidikan Matematika Raflesia, 06(01), 50-59.

Albanese, V., \& Perales, F. J. (2015). Enculturation with Ethnomathematical Microprojects: From Culture to Mathematics. Journal of Mathematics \& Culture, 1(9), 1-9.

Astriandini, M. G., \& Kristanto, Y. D. (2021). Kajian Etnomatematika Pola Batik Keraton Surakarta Melalui Analisis Simetri. Mosharafa: Jurnal Pendidikan Matematika, 10(1), 13-24. Astuti, O. D., \& Subiyati. (2020). Pengaruh Variasi Konsentrasi Mordan dan Waktu Fiksasi pada Pencapan Kain Kapas dengan Zat Warna Alam Kayu Teger (Cudrania Javanensis). Jurnal Teknika Atw, 231(Maret), 69-76.

Bishop, A. J. (1991). Mathematical Enculturation: A Cultural Perspective on Mathematics Education (3rd ed.). Kluwer Academic Publishers.

Creswell, W. J. (2012). Educational Research Planing, Conducting and evaluating quantitative and Qualitative Research (Vol. 148).

D'Ambrosio, U. D. (1985). Ethnomathematics and its Place in the History and Pedagogy of Mathematics. For the Learning of Mathematics, 5(February), 44-47.

Fatimah, S. S., \& Sirate. (2011). Studi Kualitatif Tentang Aktivitas
Etnomatematika Dalam Kehidupan Masyarakat Tolaki. Lentera Pendidikan, 14(2), 123-136.

Gunawan, F. I. (2019). Kajian Etnomatematika Serta Analisis Fundamental Matematis Menurut Bishop pada Industri Kain Cual Bangka Belitung. Magister Pendidikan Matematika, Universitas Sanata Dharma.

Hana. (2021). ECO FASHION - Elmodista.

Hartoyo, A. (2011). Etnomatematika Pada Budaya Masyarakat Dayak Perbatasan Indonesia-Malaysia. Jurnal Pendidikan Matematika Dan IPA, 2(1), 29-41.

Husna, F. (2016). Eksplorasi Teknik Eco Dyeing dengan Tanaman sebagai Pewarna. E-Proceedin of Art \& Design, 3(2), 280-293.

Kant, R. (2012). Textile Dyeing Industry an Environmental Hazard. Natural Science, 04(01), 22-26.

Krisnawati, Y. (2017). Kajian Etnomatematika Terhadap Tradisi Pernikahan Yogyakarta Oleh Masyarakat di Kecamatan Minggir, Sleman, DIY, Dalam Rangka Penentuan Aspek- Aspek Matematis yang dapat Digunakan Dalam Pembelajaran Matematika di SMP. Magister Pendidikan Matematika, Universitas Sanata Dharma.

Kuntari. (2006). Optimalisasi Proses Desizing, Scouring, Bleaching Dan Caustisizing Secara Simultan, Sistem Pad- Batch pada Kain Rayon VISKOSA. Jurnal Indonesian Sains Materi 
Indonesia, Indonesian Journal of Materials Scince, (Oktober), 118-123. Lisnani, L., Zulkardi, Z., Putri, R. I. I., \& Somakim, S. (2020). Etnomatematika: Pengenalan Bangun Datar Melalui Konteks Museum Negeri Sumatera Selatan Balaputera Dewa. Mosharafa: Jurnal Pendidikan Matematika,9(3), 359-370.

Nahak, H. M. I. (2019). Upaya Melestarikan

Budaya Indonesia di Era Globalisasi. Jurnal Sosiologi Nusantara, 5(1), 6576.

Nursyeli, F., \& Puspitasari, N. (2021). Studi Etnomatematika pada Candi Cangkuang Leles Garut Jawa Barat. Plusminus: Jurnal Pendidikan Matematika, 1(2), 327-338.

Rosa, M., \& Orey, D. C. (2011). Ethnomathematics: the cultural aspects of mathematics. Revista Latinoamericana de Etnomatematic, 4(2), 32-54.

Rumah Yapeka. (2019). Eco Fashion: Sebuah Perlawanan terhadap Fashion Konvensional. Yapeka or.ld.

Saraswati, R., Susilowati, D. M. H., Restuti, R. C., \& Pamungkas, F. D. (2019a). Pemanfaatan Daun untuk Ecoprint dalam Menunjang Pariwisata (Issue November). Departemen Geografi FMIPA Universitas Indonesia.

Saraswati, R., Susilowati, M. H. D., Restuti, R. C., \& Pamungkas, F. D. (2019b). Pemanfaatan Daun untuk Ecoprint dalam Menunjang Pariwisata (F. D. Pamungkas, Ed.; November).
Departemen Geografi FMIPA Universitas Indonesia.

Wirawan, B., \& Alvin, M. (2019). Teknik Pewarnaan Alam Eco Print Daun Ubi dengan Penggunaan Fiksator Kapur, Tawas dan Tunjung. Jurnal Litbang Kota Pekalongan, 17, 1-5.

Wulan, R. (2017, March 8). Usung Busana Ecoprint, Novita Yunus Bawa Langit ke India.

\section{Riwayat Hidup PENUlis Ratih Puspasari, M.Pd.}

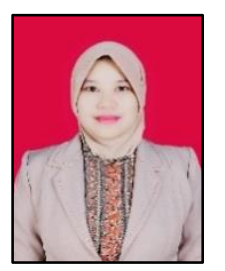

Lahir di Tulungagung, 8 Juli 1986. Staf pengajar di Universitas Bhinneka PGRI Tulungagung. Studi S1 Pendidikan Matematika Universitas Bhinneka PGRI, Tulungagung, lulus tahun 2010; S2 Pendidikan Matematika Universitas Negeri Malang, Malang, lulus tahun 2015.

\section{Anis Rinawati, S.Pd.}

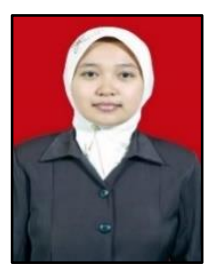

Lahir di Tulungagung, 22 Oktober 1980. Guru Matematika di SMPN 2 Kauman. Studi S1 Pendidikan Matematika Universitas Bhinneka PGRI, Tulungagung, lulus tahun 2012; S2 Pendidikan Matematika Universitas Bhinneka PGRI, Tulungagung.

\section{Anung Pujisaputra.}

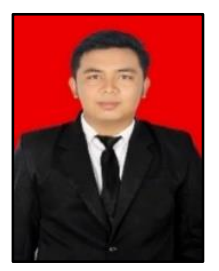

Lahir di Trenggalek, 16 Februari 1998. Studi S1 Pendidikan Matematika Universitas Bhinneka PGRI, Tulungagung, lulus tahun 2020. 